Engineering Sustainability

Volume 171 Issue ES1

Innovative approach in the stabilisation

of coastal slopes

Mickovski and Thomson
Proceedings of the Institution of Civil Engineers

Engineering Sustainability 171 February 2018 Issue ES

Pages 15-24 https://doi.org/10.1680/jensu.16.00047

Paper 1600047

Received 09/06/2016 Accepted 11/10/2016

Published online 24/11/2016

Keywords: geotechnical engineering/knowledge management/sustainability i

\title{
Innovative approach in the stabilisation of coastal slopes
}

Slobodan B. Mickovski PhD, CEng, MICE, CSCi, MCIWEM Reader, School of Engineering and Built Environment, Glasgow Caledonian University, Glasgow, Scotland, UK (corresponding author: slobodan.mickovski@gcu.ac.uk)
Craig S. Thomson PhD, FHEA

Senior Lecturer, School of Engineering and Built Environment, Glasgow Caledonian University, Glasgow, Scotland, UK

Coastal slope instability poses a risk to life and material properties and is of great concern in times of climate change, posing challenges as communities seek to adapt and ensure resilience. This paper presents two case studies of coastal slope stabilisation efforts from Scotland and reflects the growing difficultly faced by coastal communities who value intervention but are limited by uncertain ownership, funding and access to expertise. In both cases, the slopes are owned by private charities with no power of authorisation or means of procuring stabilisation works to protect the adjacent communities. The engineering solutions included an innovative eco-engineering component where vegetation was used to perform an engineering function. Based on the experience with these projects, the authors advocate this sustainable technique supported by the evidence from monitoring and testing. The case studies emphasise the importance of engaging with the community as a means of achieving acceptance of a workable solution as well as participation in its long-term development. Another significant observation was the contribution played by establishment of a learning culture that is supported through inter- and intraproject knowledge transfer deemed necessary to promote the necessary double-loop learning evident in these projects.

\section{Introduction}

The significant and lasting change in the statistical distribution of weather patterns over the long and short term manifesting as climate change (IPCC, 2013) affects all structures, in particular those on the interface between air, soil and water such as coastal slopes (e.g. natural or engineered (Meyer et al., 2010)). The design and management of these structures is traditionally based on less likely, detrimental, assumed climate characteristics that, if they happen, will bring a relatively insignificant change in terms of affecting the stability of the structure.

The stability of coastal slopes, in general, depends on the spatial and temporal distribution of weather patterns, in particular rainfall and wave action, which often trigger soil mass wasting in terms of erosion and landslips (Galbraith et al., 2005; Minder et al., 2009). In order to minimise the risk to life and property on and near coastal slopes, the potential long- and short-term impacts of climate change should be taken into account when developing a design for stability and long-term management. Despite this, only a few theoretical frameworks have been reported in the literature (e.g. Iverson, 2000; Wong et al., 2004) that account for erosion and landslides as the most frequent forms of mass wasting on slopes. These are based on analysis of historic events and systematic data collection in order to predict future behaviours, but significantly lack focus on coastal slopes. Currently, communities are not engaged in this activity, short of reporting any dramatic instability to the local authority (LA) or landowner. This limits the ability of communities to take an interest in slopes beyond the impact of catastrophic events (failure) and limits the opportunities for assessing the risks and development of preventive measures against slope instability.
In the current financial climate, when engineers and managers are tasked with providing 'more for less' or 'value for money', the main concern encompasses not only the traditional concern for slope stability (Winter et al., 2008) but also the wider question of how society and affected communities value slopes and their stability, as this has a significant impact on the sustainability and resilience of a design and management plan (Mickovski, 2014a). As competition increases for public funds, a case is required for intervention that is viewed in the interests of the taxpayer. This ultimately leaves a growing number of communities who value the stability of slopes to seek finance independently. This also raises equity concerns, with many communities suffering from being voiceless and unable to access and leverage funds. If the communities who value the stability of their slope are to deliver stabilisation through intervention, it is apparent that they need to access knowledge and expertise to help establish solutions, both engineered and natural, which represent the best value, are affordable and, in the wider context, respect the principles of sustainability.

If innovative slope stabilisation solutions are to be considered within the very limited budgets available for stabilisation, there is a need to maximise learning from past projects and balance it against an accurate assessment of risks. The shift towards this thinking has been reflected in the past decade by the inclusion of risk management within the strategic planning frameworks within which slope stabilisation projects are considered. Although not reflected by its own framework, the introduction of the climate change mitigation directive (European Commission, 2014), natural disaster risk management, shoreline management plans, catchment flood 
plans and flood and coastal risk management strategies has set a context for a holistic approach to minimising coastal slope risks and enhancing resilience. The inclusion of learning from the past has only been tacitly considered in the codes of practice.

Apart from financial aspects such as the available budget, projects are increasingly required to consider both social aspects such as public participation, risk and social resilience, and environmental aspects closely connected to climate change, such as whole-life costing and carbon dioxide footprint. Current local, national and transnational strategic planning strategies seek to promote cultural change and target investment through a proactive and inclusive approach that pulls stakeholders together to promote dialogue between the strategic level (policy makers, regulators and funders), project teams and local communities (McFadden et al., 2009). Such an approach to coastal slope management has the potential to move beyond the dominant learning style, which is single loop, and to promote instead a more reflective approach supporting double-loop learning (Voss and Wagner, 2010). Double-loop learning entails the modification of goals or decision-making rules in the light of experience, where the first loop uses the goals or decision-making rules and the second loop enables their modification, taking into account the changes in the surroundings (Argyris, 1991). This widens the evidence base for design and management (Astley-Reid et al., 2013; Thomson et al., 2014), promoting mediation and transparency. This approach also permits local systems to question and share learnt experiences and ultimately enhance the ability to respond to complex briefs within constrained budgets. Astley-Reid et al. (2013) explored the potential presented for community-led flood and coastal management projects, demonstrating the potential of local leadership and their access to receiving grants from UK and Scottish governments. This culture is advocated to promote innovation and avoid overengineered projects that are costly and disproportionate and instead support solutions that are accepted and are sensitive to local needs (Schmidt-Thomé and SchmidtThomé, 2007). With already restricted finances available for coastal stabilisation projects, the situation is exacerbated by the challenge of raising finance for the increasing instance of contested spaces where land and risk ownership remains unclear. For coastal communities, there is a need to ensure that opportunities are provided between projects, enabling innovative solutions to be found without always having to reinvent the wheel or spend limited budgets on expensive consultants. It is also necessary that communities be informed not only of the options and implications of intervention but also of the decision to allow the slope to fail. With limited finance available for intervention, it is possible that the best-value solution may be to sacrifice existing property and infrastructure. Communities require knowledge and expertise to be able to make informed decisions as well as an environment for dialogue and mediation.

This study, through case study analysis, aims to demonstrate the current coastal slope engineering and management strategies in Scotland by investigating past interventions. Through qualitative research, the study aims to explore whether promoting a wider community approach has helped promote a change in perspective in terms of the interplay between the three sustainability pillars (social, economic and environmental) in decisions taken and the degree of participation in the long-term future of slopes. The innovative approach of using eco-engineering techniques for stabilisation and management of coastal slopes is analysed in the light of risk, sustainability and resilience, as well as stakeholder engagement, innovation and double-loop learning. The case studies seek to inform how communities with contested spaces can learn from other projects with a view to overcoming barriers linked to funding, inability to draw on expert knowledge and apathy beyond a catastrophic event. A stabilisation and management framework in the context of risk and learning is proposed, drawing attention to the use of double-loop learning in the development of innovative strategies for design and management of coastal slopes in a changing climate where ownership, community engagement and funding availability are the most important factors shaping the potential for innovation.

\section{Methodology}

To outline the types of problems associated with the management of coastal slopes in Scotland, a case study approach was used to establish an understanding of current practice by comparing and critically analysing two case studies that are within a similar locality, climate and topography and are experiencing similar instability problems, shared planning regulations, local culture and many of the same stakeholders. This approach allowed the authors to make an empirical enquiry analysing engineering, managerial and social concepts and phenomena in their 'real-life context' (Yin, 1994). As this research is problem based, this descriptive and explanatory approach provides a pragmatic analytical framework around which to explore the complexity and challenge of delivering coastal slope management, analysing design, decisions, policies, institutions and stakeholder engagement.

Two study areas in north-east Scotland (Figure 1(a)) were chosen to illustrate the problems associated with the instability of coastal slopes and the management of remediation providing stability and resilience in both the short and long term. Bervie Braes is a project where slope stabilisation funding was secured based on the sufficient risk identified and where, through community engagement in the design and management of the stabilisation works, an innovative eco-engineering approach was delivered. Catterline Braes is a slope experiencing similar problems in the local area but represents a contested space where ownership and accountability for the risk among stakeholders has made securing funding difficult. This project has an active community who are keen to find a solution and to utilise the learning achieved through the Bervie Braes project. Published information was extensively studied, and a number of site visits were carried out within a 4-year period to monitor the processes occurring on both slopes and the management strategies applied. Thirteen semi-structured interviews with a range of stakeholders such as the LA, engineers and members of the communities adjacent to the study sites were also conducted within 

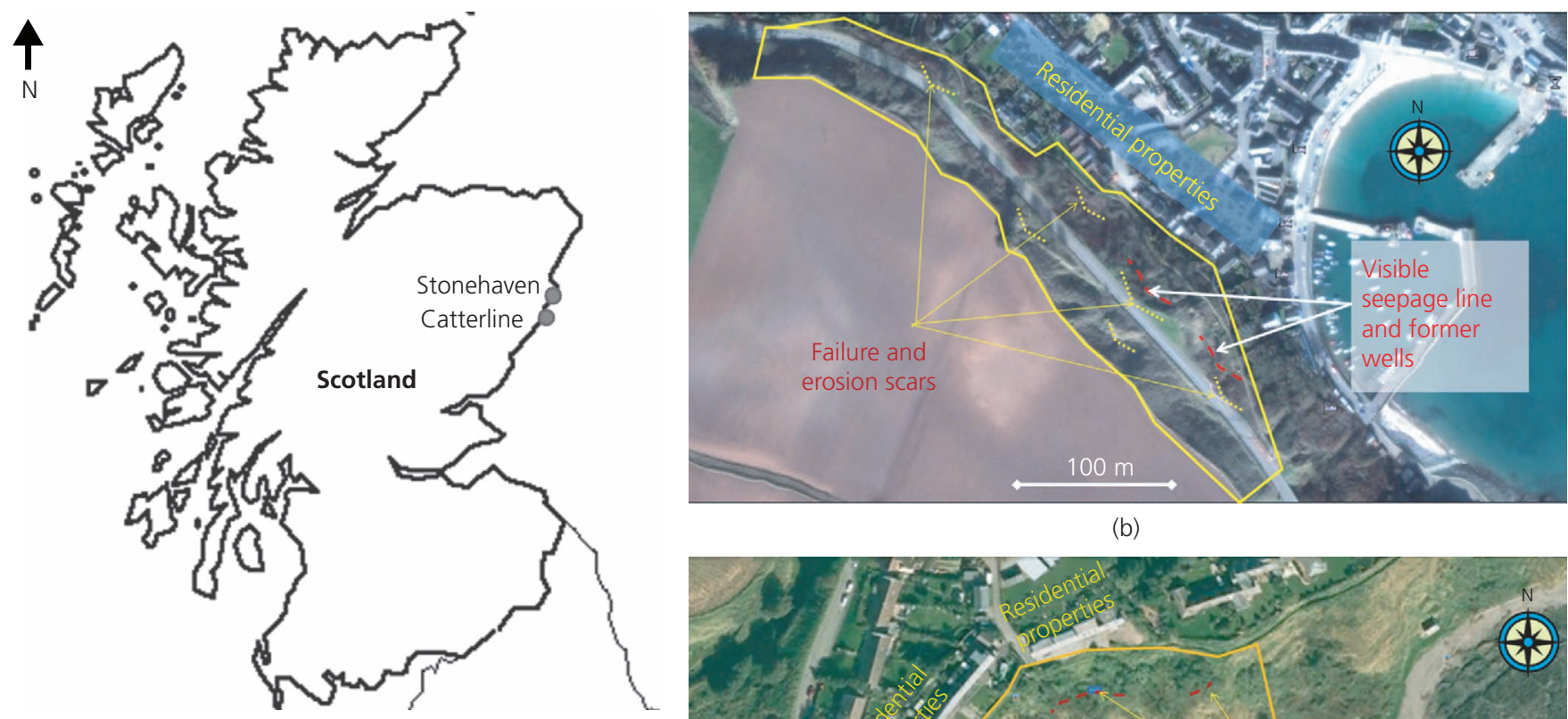

(b)

(a)

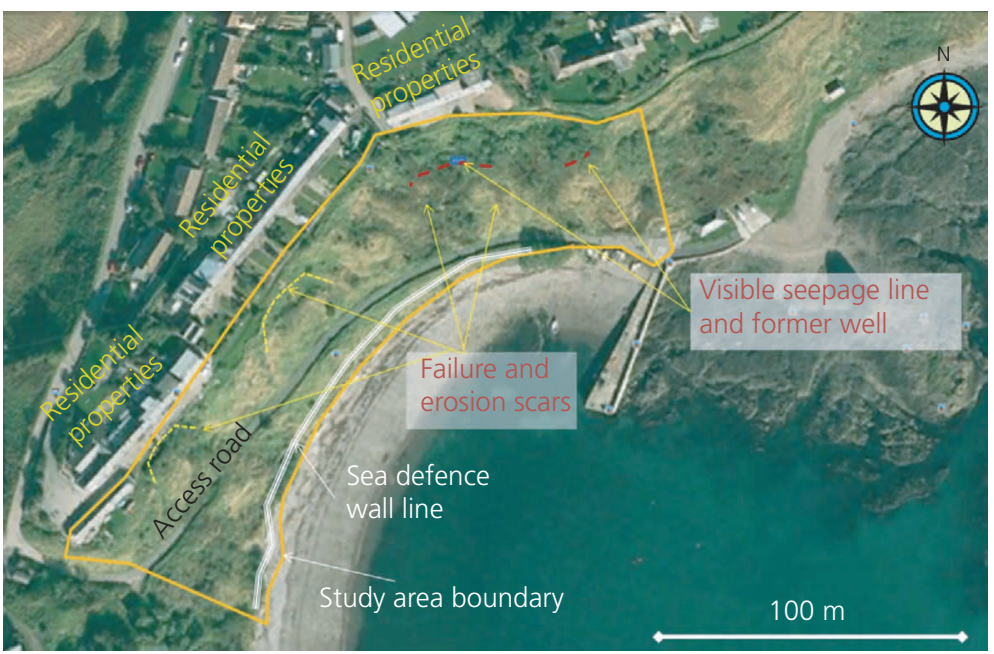

(c)

Figure 1. (a) Location of the study sites. General arrangement and instability characteristics of the coastal slope in (b) Stonehaven (Bervie) and (c) Catterline (source: (C) Google Earth, 2014)

this period with key themes emerging from the voices of the parties involved. Interviews were recorded, transcribed and then analysed using thematic analysis (Braun and Clarke, 2006).

\subsection{Background of the case studies}

\subsubsection{Bervie Braes (Bervie)}

Bervie comprises an $850 \mathrm{~m}$ long, $55 \mathrm{~m}$ high vegetated coastal slope west of the old harbour in Stonehaven, Aberdeenshire. The former trunk road connecting Stonehaven to Dunnottar Castle and the A94/A957 road runs sidelong and generally north-west to southeast across the slope (Figure 1(b)). Around 60 residential properties lie towards the toe of the slope, with the residents using the Braes for pedestrian access to the road and the nearby tourist attractions. The slope profile above the road is made up of a series of hollows, mounds and bulges, which represent washouts from ephemeral springs, failed material during one or more historical instability events (Table 1) and areas of ongoing creep, respectively. On the slope below the road, a seepage line is visible around the locations of former public wells used to provide drinking water for Stonehaven. The overlapping of old, apparently inactive, and active areas of slope instability gives the slope its hummocky appearance (Currie et al., 2009). A watercourse runs from the agricultural land above the Braes down a gully in the slope and was culverted beneath the road near the north-western end of the study area leading to the adjacent burn, which, in turn, partly causes periodic flooding to the old town of Stonehaven.

\subsubsection{Catterline Braes (Catterline)}

Catterline is a $300 \mathrm{~m}$ long, $30 \mathrm{~m}$ high coastal slope forming the north-eastern end of Catterline Bay in Aberdeenshire, Scotland (Figure 1(c)), located along the coast $10 \mathrm{~km}$ south of Bervie. Catterline comprises a series of exposed, mainly vegetated slope sections interspersed with gully outcrop forms with heights ranging between 2 and $10 \mathrm{~m}$. The slope is vegetated with a range of vegetation types, including grasses, herbs, shrubs and planted trees, covering the slope to a degree varying seasonally 


\begin{tabular}{|c|c|c|c|}
\hline Year & Event & Consequence & Action (carried out by) \\
\hline 1958 & $\begin{array}{l}\text { Major slip above the south pier } \\
\text { of the harbour }\end{array}$ & Collapse of a road section & Anchored sheet pile wall installed (LA) \\
\hline 1950s-1970s & $\begin{array}{l}\text { Drains and water supply } \\
\text { channels blocked }\end{array}$ & Vegetation overgrowth & $\begin{array}{l}\text { Burning vegetation on the slope at the } \\
\text { end of the summer }(R)\end{array}$ \\
\hline $1980 \mathrm{~s}$ & Slope failure at far western end & Major damage to residential property & Debris cleared, damage reinstated ( $R, L A)$ \\
\hline 1992 & $\begin{array}{l}\text { Distortion of the carriageway } \\
\text { surface }\end{array}$ & Cracked pavement & $\begin{array}{l}\text { Temporary single carriageway operation } \\
\text { introduced (LA) }\end{array}$ \\
\hline 1993 & & $\begin{array}{l}\text { Localised bulging of the slope and } \\
\text { development of longitudinal cracking } \\
\text { along the footpath on the } \\
\text { embankment }\end{array}$ & $\begin{array}{l}\text { Permanent closure of road in one direction } \\
\text { (uphill) (LA) }\end{array}$ \\
\hline 1994 & $\begin{array}{l}\text { Slope failures above and below } \\
\text { the road due to heavy } \\
\text { continuous rainfall over a } \\
\text { period of } 4 \mathrm{~d}\end{array}$ & Road blockage & $\begin{array}{l}\text { Debris cleared; full road closure between } \\
\text { February and July (LA) }\end{array}$ \\
\hline 2009 & $\begin{array}{l}\text { Surface washouts and mud } \\
\text { flows at the south-east end; } \\
\text { major slip at the far western } \\
\text { end }\end{array}$ & $\begin{array}{l}\text { Undermined road embankment; } \\
\text { major damage and abandonment of } \\
\text { residential property }\end{array}$ & $\begin{array}{l}\text { Full road closure; commissioning of a } \\
\text { forensic study to determine the } \\
\text { relationship between the local } \\
\text { groundwater regime, including perched } \\
\text { water levels, the locations of weak, } \\
\text { sensitive soils and the movement and } \\
\text { progressive failure of the road (LA) }\end{array}$ \\
\hline
\end{tabular}

LA, local authority; R, residents

Table 1. Timeline of instability events at Bervie Braes

(approximately $20 \%$ in winter to approximately $80 \%$ during the vegetative period). A small tarmacked access road traverses the slope from south-west to north-east, dropping in level towards the concrete landing stage on the north-east end of the bay. A gravel drain runs along the road, discharging into the sea near the landing stage. Private residential properties are located along the crest of the slope, with a grassed, non-fenced public footpath offsetting them from the slope. A branch of the footpath leads to a midslope structure - a former pumping station used in the past for freshwater supply to the adjacent properties. A seepage line is visible adjacent to the pumping house, as well as $25 \mathrm{~m}$ north of the pumping house, indicating a series of springs with seeping water flowing along naturally formed gullies towards the gravel drain along the access road, which, in turn, discharges into the sea at the landing stage, which is used by the local diving club. Remnants of a sea wall defence comprising sections of rounded boulders, mass-poured concrete, anchored gabions and concrete cubes exist at the toe of the slope and delineate the slope from the beach. The line of the sea wall is damaged to various degrees due to the action of the waves and seepage from the slope.

\section{Results}

3.1 History of problem and management at Bervie Previous instability and erosion events on the slope (Table 1) were indicated to be the consequence of shallow groundwater, oversteepened ground profiles (Currie et al., 2009) and extreme rainfall events. The LA historically used traditional engineering measures to repair failures of the slopes adjacent to the road (Table 1) that they own. The Braes is owned by a charitable trust that has no direct funding for upkeep and maintenance of the location. The LA declined adopting the Braes from the trust due to potential risks associated with instability that would impact the residential properties at the toe of the slope. In 2010 the LA, together with the Scottish government, raised limited funds to repair damage to the road embankment following the most recent instability events in 2009 and decrease the risk of slope instability for the future. It appointed a geotechnical engineering consultant and involved residents and the community council in the planning and design process (Mickovski et al., 2013). Innovative stabilisation works including structural and eco-engineering stabilisation (Mickovski, 2014a) were completed in 2013, and the road partially reopened the same year for cars (one-way) and pedestrians/cyclists. The eco-engineering methods employed included engineered planting and seeding of selected native vegetation in slope areas with lower risk of failure. This was supplemented by soil nails recessed into the slope and covered by biodegradable pre-seeded soil mix in areas with higher risk of failure. The design took into cognisance the potential climate change effects in terms of changes in temperatures and precipitation patterns and was chosen by the community at risk of instability (Mickovski, 2014a, 2014b). 


\subsection{History of problem and management at Catterline} Landslide activity along the slope (Table 2 ) has been historically linked to the springs, surface water flow and areas of ongoing creep (Figure 2(a)). The LA reactively employed traditional engineering strategies for slope stability together with the residents, albeit the slope has effectively no owner. The infrastructure belonging to the water utility stakeholder is located on the slope, while no ownership of the sea wall defence could be established. In the 1980s, the slope was owned by a trust founded by a resident, but after the trust went into liquidation in the early 1990s, the ownership status has not been resolved.

During a storm in 2013, high waves topped the sea wall, eroded the lower slope and overturned and dislocated sections of the sea wall defences. This collapse allowed the movement of the soil on the slope (Figure 2(b)), which resulted in subsidence of the access road embankment. It is possible that this failure could migrate upslope and lead to further instability, potentially affecting the properties at the crest. After this event, the local community asked for help from the LA, who, due to limited budget and perception of low risk, commissioned an earthwork contractor to repair the road and reinstate the sea wall, which was damaged by sea action later the same year, leaving a large portion of the slope toe exposed to the waves. The local community then started to look for help and assistance elsewhere to minimise the risks to their property and life. An innovative approach based on the lessons learnt from Bervie to see at least mitigation of the current instability is currently sought by the community. The use of such an approach would be aimed at employing eco-engineering strategies, such as the sustainable use of vegetation, to provide erosion protection and resistance against shallow landslides. This can be combined with structural stability measures in the areas of highest risk of instability (Mickovski, 2014b).

\section{Analysis and discussion}

\subsection{Innovative design and management}

The analysis of the history of the problems and their management showed that the case study sites have similar geology, climate and environment, which allows the innovative design and management of stabilisation measures and experiences at Bervie to be used at Catterline to minimise the risks and provide resilience. The risk of shallow and deep failures as well as erosion and flooding associated with the effects of climate change

\begin{tabular}{|c|c|c|c|}
\hline Year & Event & Consequence & Action (carried out by) \\
\hline 1940 & Slips at slope toe & Coastal erosion & $\begin{array}{l}\text { Mass concrete and concrete block sea defence } \\
\text { wall built along a section of the beach (LA) }\end{array}$ \\
\hline 1950s-1970s & $\begin{array}{l}\text { Drains (ditches) and water } \\
\text { supply channels blocked }\end{array}$ & Vegetation overgrowth & $\begin{array}{l}\text { Burning vegetation on the slope at the end } \\
\text { of the summer }(\mathrm{R}) \text {; cleaning of the drain } \\
\text { channels }(L A)\end{array}$ \\
\hline 1965 & $\begin{array}{l}\text { Slip at the crest of the } \\
\text { slope }\end{array}$ & $\begin{array}{l}\text { Mass wasting, buried existing well } \\
\text { and pump on the slope }\end{array}$ & $\begin{array}{l}\text { Manual clear-up of the failed soil; extended sea } \\
\text { defence wall by anchored gabions ( } R, L A)\end{array}$ \\
\hline 1980 & Sheet erosion of the slope & $\begin{array}{l}\text { Surface water flow on the slope and } \\
\text { access road }\end{array}$ & Drains trench built along the access road (LA) \\
\hline 1983 & Debris flow & Mass wasting on the access road & $\begin{array}{l}\text { Manual cleanup; willows planted in a small } \\
\text { section of the slope }(R)\end{array}$ \\
\hline 1994 & Major slip at slope crest & Subsidence, soil mass wasting & $\begin{array}{l}\text { Sheet piles installed to support ground in front } \\
\text { of the house; attempt at ground investigation } \\
\text { and monitoring (LA) }\end{array}$ \\
\hline 1995 & $\begin{array}{l}\text { Major slip at slope crest at } \\
\text { the same location as that } \\
\text { in } 1994\end{array}$ & $\begin{array}{l}\text { Subsidence, soil mass wasting; } \\
\text { blocked drains }\end{array}$ & $\begin{array}{l}\text { Excavation into the slope and installation of } \\
\text { gabion baskets }(\mathrm{LA})\end{array}$ \\
\hline 2000 & $\begin{array}{l}\text { Slip at slope crest near the } \\
\text { entry to the access road }\end{array}$ & Blocked access road & $\begin{array}{l}\text { Slope re-graded and anchored geotextile } \\
\text { installed }(R)\end{array}$ \\
\hline 2005-2012 & $\begin{array}{l}\text { Slip along the } \\
\text { embankment of the } \\
\text { access road }\end{array}$ & $\begin{array}{l}\text { Subsidence of a section of the access } \\
\text { road; cracking in the pavement; } \\
\text { drains dysfunctional }\end{array}$ & $\begin{array}{l}\text { Subsided areas 'topped up' with tarmac and } \\
\text { surface water directed over the pavement and } \\
\text { into the embankment (LA) }\end{array}$ \\
\hline 2013 & $\begin{array}{l}\text { Damaged sea wall } \\
\text { defence and slips of the } \\
\text { slope behind the wall }\end{array}$ & $\begin{array}{l}\text { Subsidence of the access road, mass } \\
\text { wasting and erosion of soil behind } \\
\text { wall }\end{array}$ & $\begin{array}{l}\text { Reinstatement of damaged concrete blocks; } \\
\text { attempt at ground investigation on the slope } \\
\text { (LA) }\end{array}$ \\
\hline
\end{tabular}

LA, local authority; $R$, residents

Table 2. Timeline of instability events at Catterline Braes 


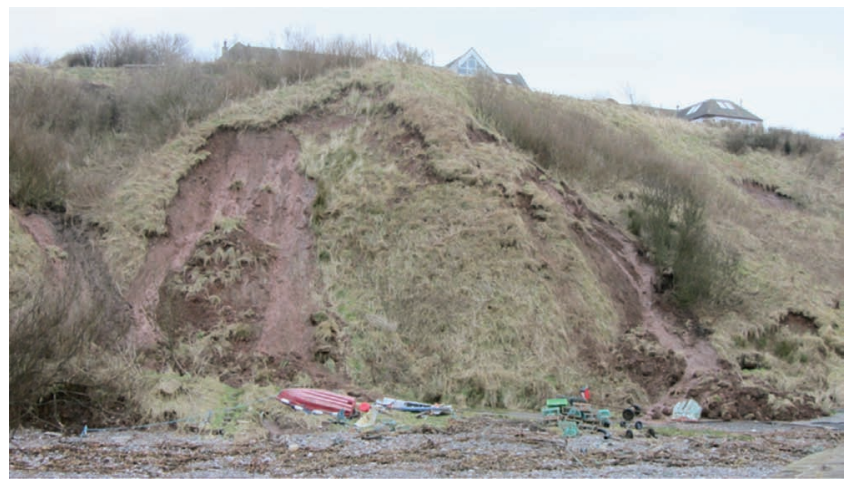

(a)

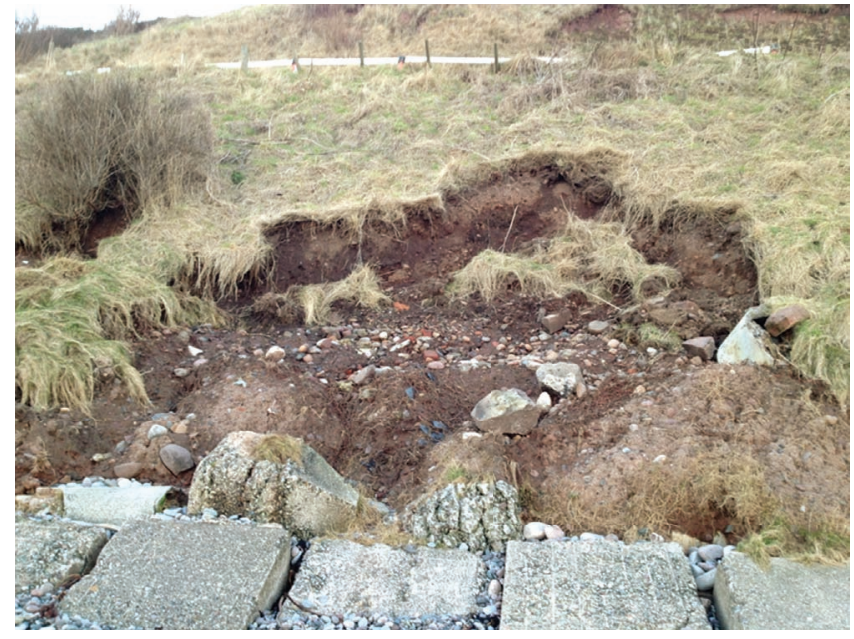

(b)

Figure 2. (a) Shallow translational slides and mudflow; (b) deeper

slides behind the sea wall defence

(Mickovski, 2014a) exist at both sites and affect residential properties and infrastructure alike. At Bervie (Figure 3(a)), resistance to catastrophic landslides is provided by soil nails and a reduction in erosion and increased resilience with easier recovery from any potential shallow slips is provided through sustainable use of vegetation. The same approach could be modified at Catterline, where a new or repaired and enhanced sea wall defence (Figure 3(b)) could be designed to adapt to climate change impacts and combined with an eco-engineering strategy (Norris et al., 2008) that will mitigate the effects of historical instability on the slope in order to provide resilience in the long term. Additionally, based on the interviews with the communities at both Bervie and Catterline, resilience in the short term and sustainability benefits (e.g. provision of recreational space) could be provided for Catterline in terms of design for reliability and durability by taking into account the changing role of vegetation in erosion protection and slope stability at various temporal scales (González-Ollauri and Mickovski, 2014; Tardio and Mickovski, 2016). This innovative solution has an added sustainability value in terms of minimal maintenance in the long term. Also, it would increase the recreational value of the coastal slope, such as pedestrian or cycling access to tourist attractions at Bervie and the local fishermen and the diving club at Catterline.

For innovative solutions to be delivered that reflect the complexity of the risk and slope, local needs and financial constraints, the conditions for creativity need to be in place, but significant management support is also required for their implementation. In both projects, an important component was discourse between the stakeholders, ensuring that they were receptive to ideas, informed about the potential risks and responsive to the construction and maintenance plans for the slope. The inclusive nature of the projects promoted a culture that not only was capable of supporting a creative design process, but also aided in achieving mediation, learning and trust in the engineers' technical judgement. The varied natures of the engagement approaches were important, with a mix of face-to-face meetings, informal discussions, community public meetings and a fly-by presentation to visually represent the design to the community. Building relationships, establishing trust and enabling openness during discussions helped the designers to not only reflect local knowledge but also facilitate community understanding and acceptance of the proposals and their implications (for construction phase disruption and in the long term). In the early stages of a project, this not only informs its development but also aids the creativity process required for innovation in design, which otherwise may not have been possible. However, if wrongly managed, the potential exists for engagement to act as a barrier to innovation. The radical nature of this solution would be reduced if, for example, the stakeholders and the wider community lacked trust in the engineering team, there is uncertainty over the risk presented or if too much effort is required to make a decision.

The approach of integration of a slope stabilisation project within a risk management framework could be implemented at Catterline based on the promotion of experiential learning from Bervie (Figure 4). This would be a change from the way these problems have been managed in the past (see Tables 1 and 2) and in line with the current (trans)national planning strategies. This shift reflects the new paradigm advocated for managing environmental projects within the current policy context, which encourages stakeholders to reflect and learn lessons from the past and other projects in order to help facilitate solutions based on innovative practice. In the case studies, this was done by using close proximity, sharing of knowledge and experience between the stakeholders through informal and formal mechanisms such as local meetings and sharing of expertise with the consistent stakeholders, including the design engineer. 


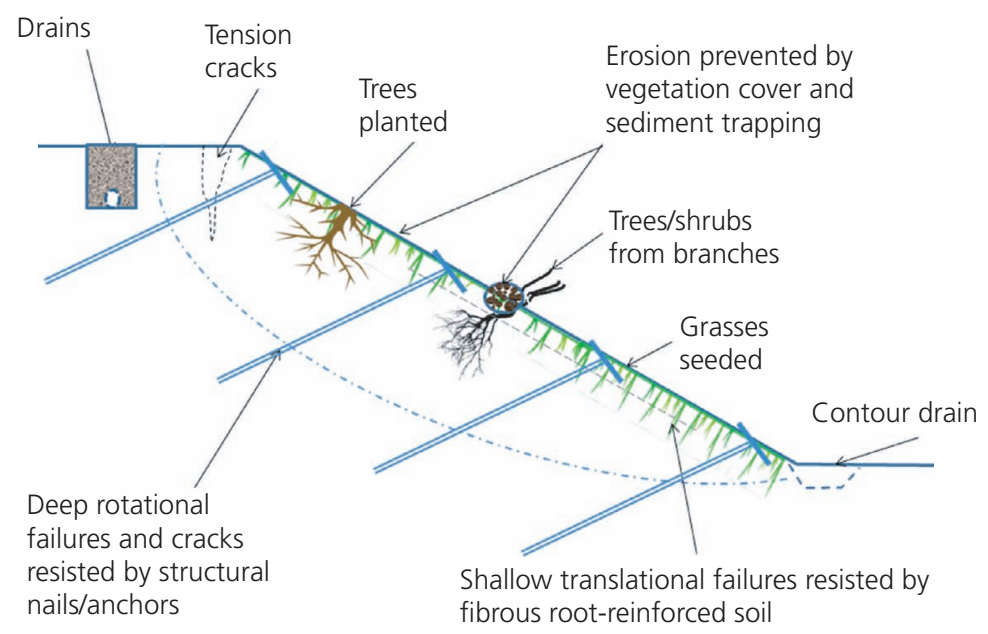

(a)

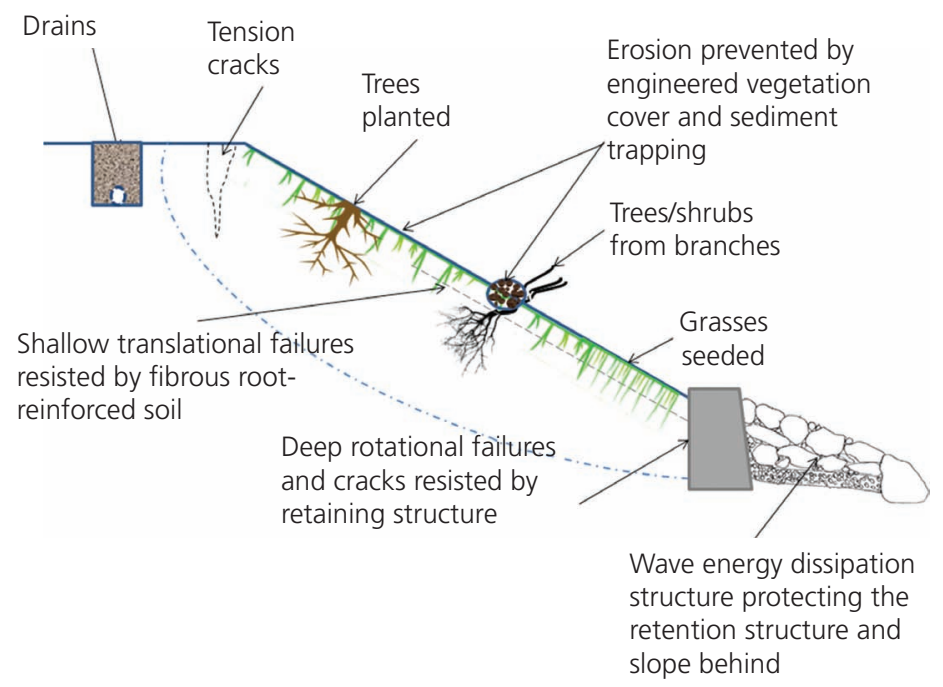

(b)

Figure 3. Integrated engineering solutions that (a) were applied at Bervie and (b) could be applied at Catterline

\subsection{Sustainability and risk}

Reflecting the current state of management of unstable coastal slopes in Scotland, the two case studies not only showed that risks to life and property were the main drivers of actions leading to stabilisation but also identified site ownership and funding for works as constraints in the process. The ownership status of the sites presented limitations that, without community leadership, could stall the project due to uncertainty. At Bervie, the LA took ownership of the slope failure risks due to historical ownership of the road on the slope, and the stabilisation works were procured. Catterline is a contested space, with only the water authority owning assets, but it has not engaged in consultation to date. Furthermore, in the absence of a risk owner, the community is forced to explore sources of funding for stabilisation works as a community project. In developing a community project, ownership problems can be overcome if a case for reducing risk, building resilience and aiding the common good can be established as a basis for funding applications (Astley-Reid et al., 2013). Supporting communities to self-organise and represent themselves as they see fit is important, and evidence suggests that this permits discourse and representation that is appropriate and meaningful (Manzo and Perkins, 2006). Such support would be important not only to facilitate intervention when appropriate, but also to support community dialogue over the implications when controlled slope failure is the best perceived course of action. However, communities would be facing real and difficult challenges if they were to sacrifice (abandon) property or infrastructure and the decisions to be taken would require knowledge, self-organisation and mediation of views.

The limited funding raised at Bervie precluded stabilisation of the whole slope below and above the road. The engineer had to assess further the risks of instability and prioritise areas for stabilisation, 


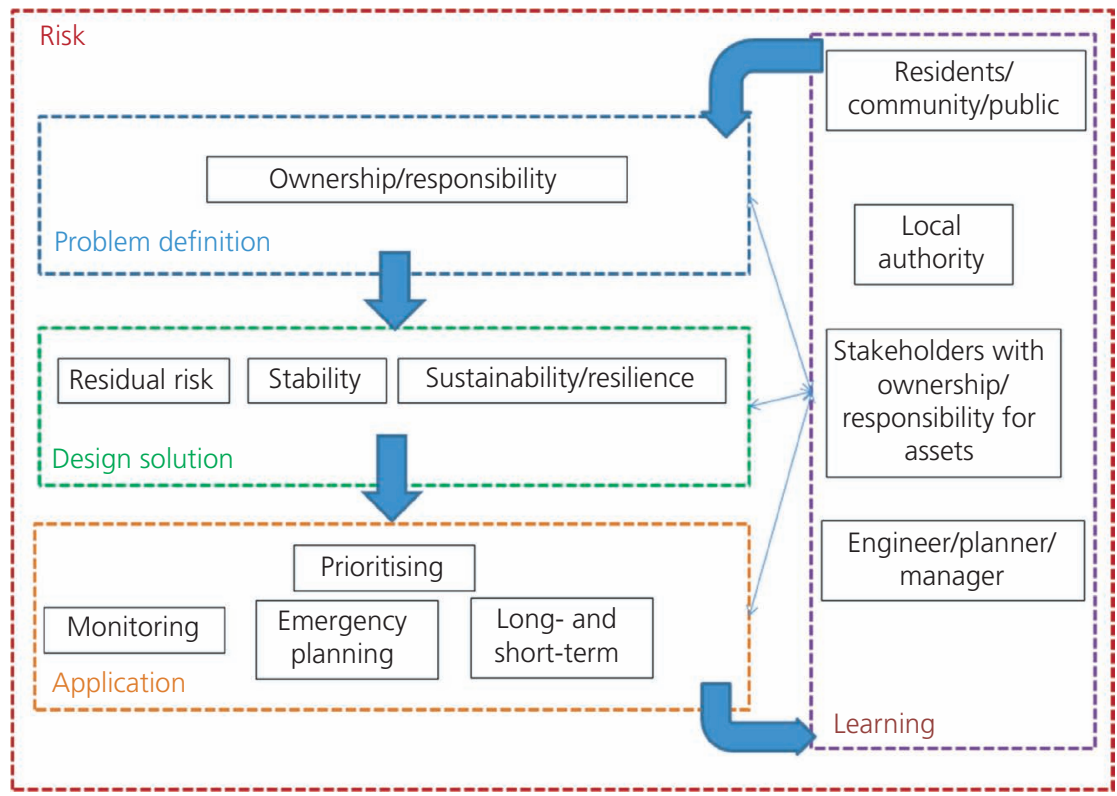

Figure 4. Proposed stabilisation and management framework in the context of risk and learning as used at the case study sites

resulting in stabilisation of $60 \%$ of the slope below the road. The rest of the slope is remotely monitored, and stability is reassessed during/after any critical rainfall event as part of the emergency plan developed by the LA and the engineer in co-operation with the residents. At Catterline, the community managed to cover approximately $40 \%$ of the slope by the planting of more than 850 trees and shrubs in priority areas, as specified by the engineer, through grants from the Woodland Trust. This demonstrates that community leadership plays a significant role in promoting involvement in the design process, aiding local needs and arriving at an appropriate solution that reflects the perceived risk and funding context. However, due to lack of funding, long-term monitoring and emergency planning at Catterline will depend on research interest from academia and the motivation of the residents.

This approach will have implications on the current standards and codes of practice, which will have to be synchronised to allow implementation. Because of the multi-disciplinarity of such projects, the possibility of this type of design framework will have to be included in the standards/codes of practice for environmental and spatial planning and geotechnical and hydrological engineering as a minimum. The inclusion in the codes of practice may be facilitated with the development of specific key performance indicators for recording and monitoring the sustainability of such projects (e.g. environmental geotechnical indicators (Jefferson et al., 2007)).

\subsection{Stakeholder engagement}

Both case studies demonstrated that projects which are inclusive of stakeholders at the strategic, project and community levels enhance evidence provision, aiding the awareness, identification and understanding of the risk presented. This facilitated the consideration by engineers of suitable design solutions and, when shared with the community, promoted discourse, mediation of views, their input to help evolve the design and ultimately acceptance (Mickovski, 2014a, 2014b). The discourse between the stakeholders at Bervie ensured that they were receptive to ideas (e.g. move away from traditional reactive engineering in order to provide sustainability value for the community represented in the decision-making), were informed about the potential risks and were responsive to the construction and maintenance plans for the slope (e.g. community pressure to reopen the road with a cycling lane in response to the known risks while given the opportunity to report any maintenance issues directly to the LA). These could not be achieved at Catterline due to a non-responsive stakeholder. The inclusive nature of the Bervie project promoted a culture that was not only capable of supporting a creative design process, but also aided in achieving mediation, learning and trust in the engineer's technical judgement. On the other hand, the engagement of the community in Catterline with academia (e.g. establishing community liaison with academia and industry) led to external charitable funding allowing the design and construction of preventive measures as well as training (e.g. workshops) on monitoring and managing of the slope.

The varied natures of stakeholder engagement approaches at both study sites were important and included a mix of face-to-face meetings, informal discussions, community public meetings and presentations to represent visually the design to the community. In the interviews with parties from both sites, levels of engagement were observed to be significant compared with similar projects, mainly due to strong self-organisation, interest and willingness to be involved. On the other hand, building relationships, establishing trust and enabling openness during discussions not only helped the 
engineers reflect local knowledge but also facilitated community understanding and acceptance of the proposals and their short- and long-term implications. In the early stages of a project, this not only informs its development but also aids the creativity process required for innovation in design, which otherwise may not be possible. At Bervie, the engineer and the LA demonstrated motivation and desire to innovate and develop new stabilisation and management solutions to accommodate the budgetary constraints.

\subsection{Double-loop learning}

The stakeholder engagement resulted in a set of experiences structured in such a way that the lessons learnt were an opportunity to improve further similar experiences. This marks a shift from the dominant single-loop style of learning, which restricts stakeholders to learning from problems that arise through a reactive mindset (Stienfuhrer, 2009). The recent shift in risk management within the environmental context calls for stakeholders to adopt a more reflective approach where a wide variety of evidence is evaluated with a view to learning lessons and considering these even before problems arise (Wedawatta et al., 2014). The residents at Catterline reported the benefits of the learning process based on the experiences at Bervie transferred through meetings between the members of each community, the involvement of the same engineer and the LA while being directly involved in the design and management processes. On the other hand, the engineer and the LA, together with other stakeholders involved in these projects, benefitted from local experiences and knowledge, which helped in identifying the problem and potential solutions and creating possibilities for translating these to similar circumstances elsewhere (e.g. Catterline) as experiential learning (Yin, 1994) (Figure 4).

The approach to managing coastal slopes in both of the case studies (Figure 4) highlights the need for a dynamic learning environment which ensures that the lessons learnt are carried forward by all stakeholders as they reflect on the project. A key characteristic of promoting this environment is for the project team, stakeholders and the community to be willing to explore ideas and solutions in an open and transparent manner. This led to solutions that were tailored and accepted for the local context. The Bervie case study reflects an environment that gets close to this with the evolution of the design aided by an inclusive culture (e.g. community engagement through all stages of the project, including selection of a stabilisation option and development of monitoring and risk assessment procedures for the long term) that promotes an exchange of knowledge and opportunities for social and mutual learning. The Catterline case study demonstrated a team who recognised the benefits of providing space for creative thinking and worked with the stakeholders (project and community) to achieve implementation. In the latter case, the community established long-term management practices such as development and maintenance of drainage networks, planting and maintenance of planted material and monitoring of the overall stability. Interviews revealed that realising double-loop learning within the design stage and management of stabilisation projects is not reflective of wider practice. Its value within the Catterline project was highlighted by the delivery of an innovative solution within a project that lacks the same level of public attention or pressure for a solution as at Bervie.

The research revealed the importance of intraproject knowledge sharing and learning. This took place across the project stages and is evidenced by involvement of the team and community in the design, construction and maintenance of the slope within both case studies. The exchange of knowledge between the projects through a range of expert and informal mechanisms also highlighted the benefits of interproject knowledge sharing and learning. Bervie Braes, due to its funding position, was able to acquire expertise from a design engineer and contractors able to provide the latest eco-engineering solutions. Catterline Braes, due to its limited access to funds, would have ordinarily been unable to access expert knowledge. However, due to its close geographical proximity to Bervie Braes, having many of the same stakeholders and community networks and the willingness of the design engineer from Bervie Braes to work with the Catterline Braes stakeholders, it was possible for an innovative design to emerge. The design engineer viewed the extension to work with Catterline Braes as part of his development forming the basis of academic research. This presents not only evidence of expertise but also experiential learning, which facilitates double-loop learning. Active communities who are engaged in the long-term development of the slope have been influential in promoting a practice learning culture, and this is evidenced by their involvement in its maintenance, promoting a genuine community interest for the slope.

\section{Conclusions}

In conclusion, this research showed that awareness of the risks, potential solutions and mechanisms of funding is critical in the initial stages of a community project. Evidence shows that an engaged community has a better potential to find solutions within limited funding regimes based on an understanding of the risks and willingness to accept change once the risk ownership is clear. This can promote innovation in design, but if the community or stakeholders are not engaged, it can also stifle innovation. This research also showed that when communities recognise the value and need for intervention to ensure the long-term resilience of a slope to climate change, they can be empowered to contribute to the case for securing public funds (Bervie Braes) or seek expertise and knowledge to maximise limited resources (Catterline Braes). When intervention is recognised as a necessity, this research shows that knowledge sharing between academia, industry and the community in regional, national and international contexts should be encouraged in the management of coastal slopes because, although the particular technical solutions can often be site-specific, the generic design and management principles can have a wider application and transboundary significance.

\section{Acknowledgements}

The authors would like to acknowledge the help of Aberdeenshire Council, Catterline Braes Action Group and Jacobs for access to the study sites and information. The authors thank Kimberly Wray of Innovivid for the support with the preparation of graphics for publication. 
Innovative approach in the stabilisation

of coastal slopes

Mickovski and Thomson

\section{REFERENCES}

Argyris C (1991) Teaching smart people how to learn. Harvard Business Review, May-June, pp. 99-109.

Astley-Reid T, Burch J and Thomas K (2013) Community-led Flood and Coastal Management Projects Supporting Adaptation and Localism in Suffolk and Essex. Suffolk Coast \& Heaths, Suffolk, UK. See http://www.suffolkcoastandheaths. org/assets/Projects-Partnerships/Stour-Orwell/Community-ledapproaches-July-13.pdf (accessed 30/04/2016).

Braun V and Clarke V (2006) Using thematic analysis in psychology. Qualitative Research in Psychology 3(2): 77-101.

Currie C, Murdoch W, Sallis D and Smith M (2009) Forensic investigation of a failed road at Bervie Braes, Stonehaven models and mechanisms. In Forensic Engineering - From Failure to Understanding (Neale B (ed.)). Thomas Telford, London, UK, pp. 325-334.

European Commission (2014) Environmental Impact Assessment (EIA) Directive (2014/52/EU). European Commission, Brussels, Belgium.

Galbraith RM, Price DJ and Shackman L (2005) Scottish Road Network Climate Change Study. The Scottish Executive, Edinburgh, UK.

González-Ollauri A and Mickovski SB (2014) Integrated model for the hydro-mechanical effects of vegetation against shallow landslides. International Journal of Environmental Quality 13(2014): 37-61.

IPCC (Intergovernmental Panel on Climate Change) (2013) Climate Change 2013 - The Physical Science Basis. IPCC, Geneva, Switzerland.

Iverson RM (2000) Landslide triggering by rainfall infiltration. Water Resources Research 36(7): 1897-1910.

Jefferson I, Hunt DVL, Birchall CA and Rogers CDF (2007) Sustainability indicators for environmental geotechnics. Proceedings of the Institution of Civil Engineers - Engineering Sustainability 160(2): 57-78, http://dx.doi.org/10.1680/ensu.2007.160.2.57.

Manzo L and Perkins D (2006) Planning common ground: the importance of place attachment to community participation and planning. Journal of Planning Literature 20(4): 335-350.

McFadden L, Penning-Rowsell E and Tapsell S (2009) Strategic coastal flood-risk management in practice: actors' perspectives on the integration of flood risk management in London and the Thames Estuary. Ocean \& Coastal Management 52(12): 636-645.

Meyer MD, Amekudzi A and O'Hare JP (2010) Transportation asset management systems and climate change. Transportation Research Record 2160: 12-20.

Mickovski SB, Black JD and Smith MJ (2013) Innovative use of ECC (NEC3) for procurement and management of infrastructure projects with limited funding: Bervie Braes case study. In Proceedings of the 29th Annual ARCOM Conference, Reading, UK (Smith SD and Ahiaga-Dagbui DD (eds)). Association of Researchers in Construction Management, Reading, UK, pp. 799-808.

Mickovski SB (2014a) Resilient design of landslip prevention measures: a case study. Proceedings of the Institution of Civil Engineers - Forensic Engineering 168(2): 96-106.
Mickovski SB (2014b) Why is the future ready for environmental geotechnics? Environmental Geotechnics 3(2): 63-74.

Minder JR, Roe GH and Montgomery DR (2009) Spatial patterns of rainfall and shallow landslide susceptibility. Water Resources Research 45: W04419, http://dx.doi.org/10.1029/ 2008 WR007027.

Norris JE, Stokes A, Mickovski SB et al. (2008) Slope Stability and Erosion Control: Ecotechnological Solutions. Springer, Dordrecht, the Netherlands.

Schmidt-Thomé P and Schmidt-Thomé K (2007) Natural hazards and climate change: stakeholder communication and decisionmaking processes. Management of Environmental Quality: an International Journal 18(3): 329-339.

Stienfuhrer A (2009) Communities at Risk: Vulnerability, Resilience and Recommendations for Flood Risk Management. HR Wallingford, Wallingford, UK.

Tardio G and Mickovski SB (2016) Implementation of ecoengineering design into existing slope stability design practices. Ecological Engineering 92: 138-147, http://dx.doi. org/10.1016/j.ecoleng.2016.03.036.

Thomson C, Mickovski S and Orr C (2014) Promoting double loop learning in flood risk management in the Scottish context. In Proceedings of the 30th Annual ARCOM Conference, Portsmouth, UK (Raiden AB and Aboagye-Nimo E (eds)). Association of Researchers in Construction Management, Reading, UK, pp. 1185-1194.

Voss M and Wagner K (2010) Learning from (small) disasters. Natural Hazards 55(3): 657-666, http://dx.doi.org/10.1007/ s11069-010-9498-5.

Wedawatta G, Ingirige B and Proverbs D (2014) Small businesses and flood impacts: the case of the 2009 flood event in Cockermouth. Journal of Flood Risk Management 7(1): 42-53, http://dx.doi.org/10.1111/jfr3.12031.

Winter M, Macgregor F and Shackman L (2008) Scottish Road Network Landslides Study - Implementation. Transport Scotland, Edinburgh, UK.

Wong HN, Ko FWY and Hui THH (2004) Assessment of Landslide Risk of Natural Hillsides in Hong Kong. Geotechnical Engineering Office, Hong Kong, China, Special Project Report SPR 5/2004.

Yin R (1994) Case Study Research: Design and Methods. Sage, Thousand Oaks, CA, USA.

\section{HOW CAN YOU CONTRIBUTE?}

To discuss this paper, please email up to 500 words to the editor at journals@ice.org.uk. Your contribution will be forwarded to the author(s) for a reply and, if considered appropriate by the editorial board, it will be published as discussion in a future issue of the journal.

Proceedings journals rely entirely on contributions from the civil engineering profession (and allied disciplines). Information about how to submit your paper online is available at www.icevirtuallibrary.com/page/authors, where you will also find detailed author guidelines. 